\title{
The Importance of Detailed Component Simulations in the Feedsystem Development for a Two-Stage-to-Orbit Reusable Launch Vehicle
}

\author{
Frank Chandler, Ph.D." and Gary Grayson ${ }^{\dagger}$ \\ The Boeing Company, Huntington Beach, California, 92647 \\ Pete Mazurkivich ${ }^{\ddagger}$ \\ NASA Marshall Space Flight Center, Huntsville, Alabama, 35812
}

\begin{abstract}
To meet the requirements for the $2^{\text {nd }}$ Generation Reusable Launch Vehicle (RLV), a unique propulsion feed system concept was identified using crossfeed between the booster and orbiter stages that could reduce the Two-Stage-to-Orbit (TSTO) vehicle weight and development cost by approximately $25 \%$. A Main Propulsion System (MPS) crossfeed water demonstration test program was configured to address all the activities required to reduce the risks for the MPS crossfeed system. A transient, one-dimensional system simulation was developed for the subscale crossfeed water flow tests. To ensure accurate representation of the crossfeed valve's dynamics in the system model, a high-fidelity, three-dimensional, computational fluid-dynamics (CFD) model was employed. The results from the CFD model were used to specify the valve's flow characteristics in the system simulation. This yielded a crossfeed system model that was anchored to the specific valve hardware and achieved good agreement with the measured test data. These results allowed the transient models to be correlated and validated and used for full scale mission predictions. The full scale model simulations indicate crossfeed is viable with the system pressure disturbances at the crossfeed transition being less than experienced by the propulsion system during engine start and shutdown transients.
\end{abstract}

\section{Introduction}

To meet the requirements for the 2nd Generation Reusable Launch Vehicle (RLV), a unique propulsion feed system concept was identified using crossfeed between the booster and orbiter stages that could reduce the Two-Stage-to-Orbit (TSTO) vehicle weight and Design, Development, Test and Evaluation (DDT\&E) by approximately $25 \%$ (Fig. 1). Crossfeed implementation has been shown to be of significant benefit with use on reusable as we!l as expendable vehicles. Hî̀ order to show that crossfeed switching during ascent was feasible, a Main Propulsion System (MPS) crossfeed water demonstration test program was configured to address all the activities required to reduce the risks for the MPS crossfeed system from a Technology Readiness Level (TRL) of 2 to 4. A more detailed description of the MPS crossfeed demonstration test program is given in Ref. 1. A subscale water flow test article was designed and fabricated as shown in Fig. 2. A subscale crossfeed check valve was designed, fabricated, and acceptance tested and later installed on the subscale crossfeed test article. Also a flow transient model was developed of a subscale water flow crossfeed system and GN2 pressurization models of the booster and orbiter tanks. This flow transient model would be used to perform pretest predictions as well as, after validation, perform the full scale launch vehicle ascent simulation to prove crossfeed feasibility. To perform the transient model simulations, the EASY5 transient system modeling software was selected as the transient modeling application.

\footnotetext{
"Director, TSS Propulsion and Cryogenic Technologies, 5301 Bolsa Ave/ H012-2B201, Associate Fellow.

${ }^{\dagger}$ Associate Technical Fellow, TSS Propulsion and Cryogenic Technologies, 5301 Bolsa Ave/ H012-2B201, Senior Member.

‡Lead Subsystems Manager, Exploration and Transportation Technologies Office, MSFC/NP60.
} 
A computational fluid dynamics (CFD) model of the crossfeed check valve was developed to assess flow disturbances and internal flow dynamics. This model was required due to the unique nature and internal flow geometries that made this component different from the existing check valve models incorporated in the EASY5 component selections. This analytic model was also required to successfully integrate the pressure drop characteristics of the check valve upon closing with the overall integrated crossfeed system water hammer dynamics simulation. Comparisons of the CFD check valve simulation with the actual acceptance test data from the check valve subcontractor indicated excellent agreement. This model proved to be crucial to the successful development of the overall crossfeed system simulation.

The revised flow transient model incorporated the updated crossfeed check valve model resulting from the CFD check valve simulations, and was used to develop the entire matrix of the pretest predictions for the water crossfeed flow tests. At the completion of the tests, validation of the subscale flow transient models was performed with the test results ${ }^{2}$. Those results were applied to the development of the fullscale LH2/LOX TSTO launch vehicle models and the three-degrees-of-freedom (3-DOF) ascent simulations. The full scale model simulations indicated that crossfeed is viable with the system pressure disturbances at the crossfeed transition being less than experienced by the propulsion system during engine start and shutdown transients ${ }^{3}$.

\section{System Simulation with EASY5}

Any software or modeling approach employed must be able to address rapid pressure transients or water hammer with the capability of simulating various flow components such as valves, tees, bends, flex hoses, manifolds, etc. It must also be able to easily incorporate customized subroutines for hardware specific models and advanced physical models such as propellant tank pressurization and heat transfer. The commercially-available EASY5 software with its thermal hydraulic application library meets the above requirements and is selected as the basic platform for transient system modeling.

EASY5 is a graphical-user-interface-based software used to model, analyze, and design dynamic systems characterized by differential, difference, and algebraic equations. Models are assembled from primitive functional blocks such as summers, dividers, lead-lag filters, integrators, and application-specific components from hydraulic, mechanical, multi-phase fluid, pneumatic, and thermal libraries. Analysis tools include non-linear simulation, steady-state analysis, linear analysis, control system design, data analysis, and plotting. Source code is automatically generated to support real-time requirements. An open architecture provides easy access to a broad set of software and hardware tools used in computer-aided control systems engineering. EASY5 runs on Unix and Windows operating systems. ${ }^{4}$

\section{Crossfeed Valve System Model}

For the propellant crossfeed problem EASY5 is used to simulate one-dimensional flow in the liquid and gas flow networks. Individual components constructed from standard EASY5 models include tanks, outlets, lines, flex hoses, bends, tees, reducers, valves, and flow rate controllers. For the crossfeed check valve, however. a new transient valve model is needed. The basic check-valve model from the thermalhydraulic library in EASY5 functions as a variable-area orifice with the flow area a function of the valve delta-pressure and direction. The valve remains closed if the pressure drop is less than the specified cracking pressure. When the forward pressure across the valve equals the cracking pressure, the valve begins to open and is fully open when the pressure drop across the valve equals a fixed factor times the cracking pressure. In this simple check-valve model the user-inputted cracking pressure directly specifies the fully-open pressure drop. Although this valve model works well in many applications, for the crossfeed check valve simulation the cracking and fully-open pressures must be specified independently to represent the specific hardware used. For this reason the standard EASY5 check valve is not used and instead a new dynamics model is developed to more accurately simulate the crossfeed check valve.

The new model considers the actual mechanism in flapper-type check valves to specify the transient behavior during system simulation with EASY5. It is based on the 4" dual-flapper valve used in the crossfeed experiment, however, its formulation is generic and can be used for other check valve designs and scales. Displayed in Fig. 3 is a free body diagram for one of the flappers in the check valve where $\theta$ is the flapper displacement angle, $M_{\text {PRESSURE }}$ is the moment from pressure forces acting upon the flapper, $\mathrm{M}_{\mathrm{VIScous}}$ is the resistance to flapper motion due to movement through the fluid, and $\mathrm{M}_{\mathrm{SPRING}}$ is the moment 
applied to the flapper from springs that act to close the valve. By summing all torques on a flapper and then using conservation of angular momentum, the following equation of motion results for each flapper:

$$
\ddot{\theta} \cdot I_{Y}=f_{P} A_{F L A P} r_{C P} \cos (\theta) \cdot \Delta P-\frac{1}{2} C_{D} \rho A_{F L A P} r_{C P}^{3} \cdot \dot{\theta} \cdot|\dot{\theta}|-n_{F} n_{S} k_{S} \cdot\left(\theta+\theta_{0}\right)
$$

where $\ddot{\theta}$ is angular acceleration, $\dot{\theta}$ is angular velocity, $\theta$ is displacement angle, $I_{Y}$ is the mass moment of inertia of the flapper about its axis, $r_{C P}$ is center of pressure radius on the flapper, $f_{P}$ is the pressure distribution function which accounts for changes in the center of pressure location versus displacement angle, $A_{F L A P}$ is the area of each flapper, $\Delta \mathrm{P}$ is pressure drop across the check valve, $C_{D}$ is the effective drag coefficient, $\rho$ is liquid density, $\theta_{0}$ is the spring pre-load angle, $n_{F}$ is the number of flappers, $n_{S}$ is the number of springs per flapper, and $\mathrm{k}_{\mathrm{S}}$ is the spring constant per spring.

Two key relationships can be derived from Eq. 1. By setting $\ddot{\theta}, \dot{\theta}$, and $\theta$ to zero, $\Delta \mathrm{P}$ becomes the cracking pressure for the valve, $\Delta P_{C R A C K}$ as shown in Eq. 2 where $f_{P, C R A C K}$ is the pressure distribution value at $\theta=0$.

$$
\Delta P_{\text {CRACK }}=\frac{n_{F} n_{S} k_{S} \cdot \theta_{0}}{f_{P, C R A C K} A_{F L A P} r_{C P}}
$$

Similarly, if $\ddot{\theta}$ and $\dot{\theta}$ are zero and $\theta$ is equal to the flapper angle when the valve is fully open, $\theta_{\mathrm{FO}}$, then Eq. 1 can be rearranged to yield the fully-open pressure drop, $\Delta P_{F O}$, as shown in Eq. 3 where $f_{P, F O}$ is the pressure distribution value at $\theta=\theta_{\mathrm{FO}}$.

$$
\Delta P_{F O}=\frac{n_{F} n_{S} k_{S} \cdot\left(\theta_{F O}+\theta_{0}\right)}{f_{P, F O} A_{F L A P} r_{C P} \cos \left(\theta_{F O}\right)}
$$

The relationships in Eqs. 2 and 3 are useful for designing or scaling up the crossfeed check valves for other systems. By utilizing Eq. 1 to represent check valve dynamics the cracking pressure and fully-open pressure can be specified independently. Also, phenomena such as reverse flow and chattering of the flappers on the seats are predictable. As noted above the standard EASY5 check valve models are limited in the operating characteristics; they can not predict reverse flow and valve chatter. Modeling of reverse flow through check valves is important for accurate pressure history prediction at critical components. Valve chatter is an indication of a design problem that can reduce the life and performance of the crossfeed valve, therefore, it is also important to have this simulation capability.

\section{A. Component Simulation with FLOW-3D}

Before Eq. 1 can be solved in EASY5 for the check valve dynamics, an accurate relationship is needed for the valve's pressure loss as a function of mass flow rate and flapper displacement angle. To determine this relationship a computational fluid-dynamics (CFD) model of the valve is created with the FLOW-3D software. $^{5}$ FLOW-3D is a general Navier-Stokes equation solver with an extensive aerospace history for modeling liquid and gas systems in rockets and spacecraft. ${ }^{6-10}$ Models are constructed using $2^{\text {nd }}$-order polynomial equations and tabular functions to represent the hardware geometry, initial conditions, and boundary conditions. FLOW-3D has also been experimentally validated for transient internal flows including polymer injection molding ${ }^{11}$ and restricted flows in ducts. ${ }^{12}$ Accordingly, FLOW-3D is a versatile analysis tool and is well-suited for the modeling of internal flow through a crossfeed check valve.

1. Crossfeed Valve Component CFD Model

An image of the valve model geometry and computational mesh is shown in Fig. 4. The FLOW-3D model features and assumptions include an incompressible liquid, isothermal flow, constant liquid properties (density, viscosity, and speed of sound), $2^{\text {nd }}$-order momentum equation, renormalized group theory (RNG) turbulence model, wall shear on all solid surfaces, symmetry plane through center of valve 
across both flappers $(y=0), 616$-thousand computational cells, 4.026-inch diameter pipe, upstream pressure boundary, and downstream pressure boundary. Also, four feet of pipe are simulated both upstream and downstream to minimize the influence of the boundary conditions on the valve flow field.

Since ambient water is the test fluid and the flow Mach number is much less than 0.3 , the liquid can be assumed incompressible with negligible density variations due to pressure change. Similarly, heat transfer into the feed system will be low and thus the liquid density $(\rho)$, viscosity $(\mu)$, and speed of sound $V_{\text {sound }}$ can be assumed constant with no variation due to temperature change. Since the boundary layer flows and vortices are of interest in valve analyses, the FLOW-3D $2^{\text {nd }}$-order momentum equation is used. For turbulent flow modeling FLOW-3D's RNG turbulence model is activated. The RNG model is recommended over other turbulence options in FLOW-3D such as the k- $\varepsilon$ model due to its decreased reliance on empirical data. Wall shear or no-slip is applied at all solid surfaces in the model with the shear calculations modified by surface roughness constants. A symmetry condition about $y=0$ is applied to reduce computational run times. This is justifiable due to the lack of observable secondary flows in a preliminary model executed without the symmetry condition in the full domain.

\section{Grid Selection}

The final computational mesh selected and shown in Fig. 4 is based on a series of simulations with a similar valve model at various resolutions. In each model the predicted force on one flapper and the mean kinetic energy in the domain are observed. As the model resolution increases (thus as cell size decreases) both the flapper force and fluid kinetic energy become asymptotic towards single constant values. The final model has about 616-thousand cells to represent the half-domain with the $y=0$ symmetry condition which yields a minimum cell size near the valve mechanism of 0.08 inch. For cell sizes smaller than this the predicted results are both qualitatively and quantitatively similar, therefore, the selected mesh will provide grid results mostly unaffected by grid design.

\section{Fully-Open Pressure Drop Predictions}

Using the developed CFD model several simulations are run at various flow rates for a fully-open valve. Initially both the upstream and downstream pressure boundary conditions are set to the same value. To initiate flow through the model the downstream boundary condition is ramped down over one second to a pre-selected value. The total delta pressure across the simulation domain along with the model geometry and numerical assumptions determine the time-varying flow field in the model. The models are simulated until conditions become steady which is less than a few seconds. Typical results from the simulations are shown in Fig. 5. The flow field is complex and contains several regions where the flow stagnates, expands, and recirculates. The downstream velocity profile is shown to be significantly perturbed by the valve hardware near the center of the flow stream. Based on the series of numerical tests the following relationship between pressure drop and mass flow rate is predicted for the fully-open valve:

$$
\Delta \mathrm{P}=\mathrm{C}_{1} \cdot \mathrm{mdot}^{2}+\mathrm{C}_{2} \cdot \mathrm{mdot}+\mathrm{C}_{3}
$$

where $\Delta \mathrm{P}$ is in psid and mdot is in $\mathrm{lbm} / \mathrm{s}$, and $\mathrm{C}_{1}, \mathrm{C}_{2}$ and $\mathrm{C}_{3}$ are empirical constants. Contact the authors for these constants. Using a water density of $1.937 \mathrm{slug} / \mathrm{ft}^{3}$ at $\hat{I}$ atm and $52 \bar{\gamma} \bar{K}, \overline{E q} .4$ is converted to $\dot{\Delta} \vec{P}$ as a function of volumetric flow rate:

$$
\Delta \mathrm{P}=\mathrm{C}_{1}^{*} \cdot \mathrm{Q}^{2}+\mathrm{C}_{2}^{*} \cdot \mathrm{Q}+\mathrm{C}_{3}^{*}
$$

where $\Delta \mathrm{P}$ is in psid, $\mathrm{Q}$ is in gpm, and $\mathrm{C}_{1}{ }^{*}, \mathrm{C}_{2}{ }^{*}$ and $\mathrm{C}_{3}{ }^{*}$ are empirical constants. Contact the authors for these constants. Equations 4 and 5 are for the valve in the fully-open position when the flappers are pressed against the afterbody wedge in the valve.

\section{Model Validation}

Several flow experiments are conducted to physically measured the pressure loss through the valve as a function of flow rate. The tests are conducted with water in the apparatus illustrated in Fig. 6 and the measured results are compared to the CFD predictions. Table 1 displays the measured test results where $\Delta \mathrm{P}_{\mathrm{RAW}}$ is the delta pressure across the entire apparatus, $\Delta \mathrm{P}_{\mathrm{TARE}}$ is the pressure loss through the apparatus without the crossfeed valve installed, and $\triangle \mathrm{P}_{\mathrm{VALVE}}$ is the pressure drop through the valve which is calculated from $\Delta \mathrm{P}_{\mathrm{RAW}}-\Delta \mathrm{P}_{\mathrm{TARE}}{ }^{13}$ 
The comparison between model and experiment delta-pressure is illustrated in Fig. 7 where the solid line is the FLOW-3D model prediction described by Eq. 5 and the square symbols represent the design verification test data. As shown in Fig. 7 the model predictions and test data are in relatively close agreement. All tests are within $12 \%$ of the model predictions. This provides quantitative validation that the FLOW-3D software and the modeling techniques used provide reasonably accurate results.

However, there are some slight differences between the test and simulation conditions that should be noted. First, in all simulations the water temperature is assumed to be precisely $528{ }^{\circ} \mathrm{R}$ where in the experiment the water temperature is at local ambient conditions and is not measured. Additionally, the water warms up over time during testing due to heat input from the pump used in the closed-loop flow network. The test sequence for the cases in Table 1 (denoted by flow rate in gpm) are $640,800,855,900$,

\begin{tabular}{|c|c|c|c|}
\hline Table & \multicolumn{3}{|c|}{ Check Valve Flow Test Data } \\
\hline $\begin{array}{c}\mathbf{Q} \\
(\mathrm{gpm})\end{array}$ & $\begin{array}{l}\Delta P_{\text {RAW }} \\
\text { (psid) }\end{array}$ & $\begin{array}{c}\Delta P_{\text {TARE }} \\
\text { (psid) }\end{array}$ & $\begin{array}{c}\Delta P_{\text {VALVE }} \\
\text { (psid) }\end{array}$ \\
\hline 640 & 1.2 & 0.55 & 0.65 \\
\hline 800 & $\overline{1.8}$ & 0.80 & 1.00 \\
\hline 855 & 2 & 0.90 & 1.10 \\
\hline 900 & 2.2 & 1.00 & 1.20 \\
\hline 960 & 2.5 & 1.15 & 1.35 \\
\hline 985 & 2.6 & 1.20 & 1.40 \\
\hline 1005 & 2.7 & 1.25 & 1.45 \\
\hline
\end{tabular}
$960,985,1005$. Accordingly, the higher flow rate cases used warmer liquid than the lower flow rate cases. Since the water density and viscosity decrease with increasing temperature, the pressure losses reported would be slightly lower at the larger flow rates than the simulations which assumed the liquid was at constant temperature. It may be for this reason that the FLOW-3D predictions are higher than the test in the higher flow rate cases.

Another discrepancy is the location where pressure is measured in the model and experiment. The net pressure loss through the valve (from flange to flange) is determined with the test data by the method described above. However, the pressure field near the upstream flange is strongly influenced by the presence of the wedge forebody which is nearly flush with the upstream flange; refer to Fig. 5. Therefore, in the CFD model the pressure is measured approximately one inch upstream and downstream of the valve flanges to ensure that the pressure is monotonically changing along the direction of flow with no radial effects caused by proximity to the valve's internal hardware. Thus, if the pressures in the test were actually measured at the same location as in the CFD model, the delta pressure data would be slightly higher due to the extra two inches of pipe included in the measurement. Despite minor discrepancies discussed above the FLOW-3D model does a reasonably good job predicting pressure drop through a complex flow valve.

\section{Effect of Partially Open Flappers}

Using the validated fully-open valve model described, calculations are performed to estimate the crossfeed check valve pressure drop while partially open. A series of CFD simulations are executed with various flapper displacement angles, $\theta$ and flow rates. A fully-open valve has a flapper angle of 78.8 degrees while a closed valve has an angle of 0 degrees. Steady state solutions are calculated for four intermediate positions $(5,15,35$, and 60 degrees) plus the fully open position. In each simulation a pressure difference is specificd across the domain and the flow is allowed to develop towards steady state. The pressure loss across the valve is measured to determine valve pressure drop as a function of both flow rate and displacement angle. Pressure and velocity results are shown in Figs. 8-11 for various flapper angles. As observed in Fig. 5 flow in the fully-open valve case has a low pressure region just after the centerbody wedge expansion. At a flapper angle of 60 degrees in Fig. 8 a larger low pressure region forms on the downstream side of the flappers that replaces the small low pressure area observed at the fully-open position. As expected for obstructions in a flow stream a large velocity gradient now exists on the downstream side of the flappers. At $\theta=35$ degrees in Fig. 9 the low pressure region has increased in size from that at 60 degrees to fill the diameter of the pipe downstream of the flappers. At 15 and 5 degrees shown in Figs. 10 and 11 the valve is nearly closed with the CFD model predicting steep pressure gradients and significantly reduced flow rates over the more open cases. Using the predicted steady-state losses from the simulations, the sensitivity of valve pressure drop to partially open conditions can be approximated. Equation 6 displays a curve-fit equation for the effective valve flow area, $A_{C v}$, with valve discharge coefficient, $C_{d}$ and $K_{1}, K_{2}$ and $K_{3}$ are empirical constants. Contact the authors for these constants. 


$$
A_{C V}=\left(\frac{A_{P I P E}}{C_{d}}\right) \sqrt{\frac{1}{K_{1} \theta+K_{2} /(\theta+\varepsilon)+K_{3}}}
$$

It is generated with the results from 15 valve simulations at various flow rates and flapper displacements. The constant $\varepsilon$ is an arbitrary small number in the curve fit equation required to prevent a divide-by-zero error when $\theta=0$. Equation 6 from the FLOW-3D component analyses is then input into the EASY5 system model along with Eq. 1 to represent the crossfeed check valve dynamic behavior. This yields a high fidelity simulation that is tailored to the specific hardware used.

\section{B. Crossfeed System Testing \& Simulation}

A physical test and a computational simulation are performed to represent a reusable two-stage-to-orbit launch vehicle mission that utilizes a crossfeed propulsion system. The subscale test uses a four inch diameter feed system with water as the test fluid. Testing is conducted with the crossfeed test apparatus; pressure histories and flow rates are measured at important locations in the feed network. Such locations include the upstream and downstream sides of the check valve plus the upstream sides of the engine simulator valves. The model is run with the same operational sequence and fluid conditions as in the test to yield predictions that are compared to the measured data.

1. Operational Sequence

The sequence of events tested is illustrated in Table 2. For each event the initiation time is shown along with the associated reusable launch vehicle (RLV) event and description. Flow is initiated at $0 \mathrm{~s}$ which represents engine ignition. After a few seconds of steady flow, the engine flow rates are decreased at $5 \mathrm{~s}$ to model an engine throttle-down at maximum vehicle dynamic pressure. At $10 \mathrm{~s}$ the flows are throttled back up then at $15 \mathrm{~s}$ the booster engine flow is reduced to simulate the booster throttle-down before staging. Termination of the crossfeed flow starts at $20 \mathrm{~s}$ when the orbiter tank isolation valve is opened. At $37 \mathrm{~s}$ the simulated engine flow rates are decreased to zero to represent shutdown of the engines.

Table 2 Test and Model Operations Sequence for Two-Stage-to-Orbit Launch Simulation

\begin{tabular}{|c|c|c|c|}
\hline Time & Test Event & RLV Event & Description \\
\hline $0 \mathrm{sec}$ & $\begin{array}{l}\text { Open Booster \& Orbiter } \\
\text { Engine Valves }\end{array}$ & Launch \& Initial Ascent & Start of model simulation \& flow \\
\hline $5 \mathrm{sec}$ & $\begin{array}{l}\text { Reduce Engine Valve } \\
\text { Flow Rates }\end{array}$ & Engine Throttle-Down & $\begin{array}{l}\text { Commanded flow rate decreased to simulate } \\
\text { engine throttling for max dynamic pressure }\end{array}$ \\
\hline $10 \mathrm{sec}$ & $\begin{array}{l}\text { Increase Engine Valve } \\
\text { Flow Rates }\end{array}$ & Engine Throttle-Up & $\begin{array}{l}\text { Commanded flow rate increased to simulate } \\
\text { engine throttle-up after max dynamic pressure }\end{array}$ \\
\hline $15 \mathrm{sec}$ & $\begin{array}{l}\text { Reduce Engine Valve } \\
\text { Flow Rates }\end{array}$ & Booster Engine Throttle-Down & $\begin{array}{l}\text { Commanded flow rate decreased to simulate } \\
\text { engine throttle-down for staging }\end{array}$ \\
\hline $20 \sec$ & $\begin{array}{l}\text { Open Orbiter Isolation } \\
\text { Valve }\end{array}$ & Crossfeed Termination & $\begin{array}{l}\text { Flow from orbiter tank is initiated passively } \\
\text { termınating crossieed }\end{array}$ \\
\hline $37 \mathrm{sec}$ & Close Engine valves & MECO/SECO1 & Commanded flow rates decreased to zero \\
\hline $45 \mathrm{sec}$ & Test End & Post MECO/SECO1 & All flows stopped, end of simulation \\
\hline
\end{tabular}

2. System Model Description

The model of the crossfeed test apparatus is created with the EASY5 thermal-hydraulic library and the developed crossfeed check valve dynamics model. Figure 12 displays the model flow schematic which illustrates a large number of components simulated including the booster tank, orbiter tank, lines, bends, tees, valves, crossfeed check valve, flex hoses, and flow rate controllers. The model also has an embedded tank pressurization routine developed separately which calculates ullage pressure, pressurant use, liquid head pressure, liquid temperature, gas temperature, and tank wall temperature. The assembled analysis tool is useful for predicting feed system pressure transients and flow rates during user-specified operational sequences and environments.

3. System Model Results and Discussion

Results of the sample launch simulation are illustrated in Figs. 13-19. The pressure histories upstream and downstream of the crossfeed check valve are shown in Figs. 13 and 14, respectively. P301 is the 
sensor on the booster side of the check valve which is upstream under forward flow; P302 is the sensor on the orbiter side which is downstream under forward check valve flow. Overall the model predictions match the test data trends well. The predictions (shown in blue) overlay the test data (shown in red) near the middle of the measurements. The test data has more oscillation than the predicted curves which are much smoother shaped. This is attributed to the typical oscillatory nature of pressure transducer measurements in a feed system. At the beginning of the model the predicted pressure history deviates from the test data, but this is due to the start-up of the numerical simulation. Many computational simulations exhibit false initial transients due to non-exact initial conditions and the numerical approximations employed in the model. For this reason simulations must start at a place in time significantly before the event of interest to minimize the effects of the start-up transient. In the present launch vehicle simulation, 20 seconds of calculations are performed before crossfeed termination which is judged have a negligible influence on the results at that time.

Notice the relatively large pressure spikes and slumps during the crossfeed termination event at 20 seconds. As the orbiter isolation valve is opened the pressure on the downstream side of the check valve increases until the valve closes passively. Just before the valve closes, the flow reverses due to the now negative pressure drop across the valve. When the valve finally closes stopping all flow, a pressure slump occurs on the booster side which is now the downstream side of the check valve under the reverse flow conditions. The pressure slump then travels through the booster feed system and reflects off other components to yield an oscillating and damping pressure history at the check valve. Similarly, the orbiter side of the check valve is the downstream side during forward flow operations but becomes the upstream side during the reverse flow at crossfeed termination. Here, a pressure spike instead of a slump occurs with reflections that decay with time.

Close-up views of the pressure histories at the check valve are shown in Figs. 15 and 16. The predicted initial pressure spike and slump are in favorable agreement with the test data, where the percentage errors are $18 \%$ and $30 \%$ for the booster and orbiter sides of the valve, respectively. However, the model has more damping during the transient and different response frequencies than the test. The predicted response from crossfeed termination quickly damps just after the event, but then continues to oscillate or ring for a relatively long time afterwards. Since the line lengths from crossfeed check valve to the booster and orbiter source tanks are the same, similar booster and orbiter response frequencies are expected. Accordingly, the EASY5 model predicted a $42 \mathrm{~Hz}$ frequency for both the booster and orbiter feed system after crossfeed termination. However, the test recorded $27 \mathrm{~Hz}$ for the booster and $50 \mathrm{~Hz}$ for the orbiter thus yielding percentage errors of $54 \%$ and $16 \%$ for the booster and orbiter frequencies, respectively. These differences in response frequencies are attributed to small geometry differences between the feed systems and the presence of dissolved gas in the water supply.

The booster feed system has larger lines and more reducers than the orbiter system. Reducers and line diameter variations have been previously shown to influence wave propagation speed and in tum system natural frequency. ${ }^{14}$ Using the approach presented in Ref. 14 for rigid column theory and assuming a wave speed of $4200 \mathrm{ft} / \mathrm{s}$ yields booster feed system frequency of $55 \mathrm{~Hz}$ and an orbiter frequency of $45 \mathrm{~Hz}$. Note that this is the opposite trend of the test data which recorded a higher orbiter natural frequency.

Trapped or entrained gas, however, have been shown to drastically affect fluid system natural frequencies. $^{15}$ As little as $1 \%$ gas in a liquid feed system can reduce wave speed by $75 \%$. Since the water supply used for testing is from a large pool open to atmosphere, it is expected to have dissolved air at an equilibrium solubility pressure near 14.7 psia at the pool surface. Thus, when the test apparatus is filled, the dissolved gas is already present. This gas will quickly exit solution at locations where the pressure drops below the equilibrium solubility pressure ${ }^{16}$ which is likely to occur at restrictions, around bends, or at the flex hose convolutes. Additional gas may also be present by becoming trapped at high points in the feed system. Any gas whether entrained or trapped will affect the feed system frequencies. Unfortunately, no attempt is made to measure the amount of gas in the system during testing. However, streams of bubbles are seen continuously flowing from the outlet lines that flow back into the water pool, but no bubbles are noticed in the transparent view section near the check valve. This is the same result expected for dissolved gas that did not exit solution until decreasing enough in static pressure at the engine simulator valves. Thus, only the recorded frequencies serve as an indirect measurement of the amount of gas present. It is postulated that if the tests were repeated with no dissolved gas and more high-point bleeds the booster and orbiter frequencies would be closer in value.

The flow rate test and model results shown in Figs. 17-19 illustrate favorable agreement. FM301 is in the crossfeed line; FM102 is in the booster engine simulator line; FM202 is in the orbiter engine simulator 
line. The predicted crossfeed check valve volumetric flow rate in Fig. 17 closely matches the test data not including the sensor oscillation characteristics and the initial start-up transient of the numerical simulation. The flow rate predictions for the booster and orbiter engine simulators in Figs. 18 and 19 are in general agreement with the test data. However, the measured rapid flow rate surges and drop-offs are not mimicked by the computation. The flow meters used are of the delta-pressure type that can respond fast enough to operate at the system natural frequencies. It is unlikely, however, that the water could move fast enough to flow at these recorded rates. For example at the booster engine simulator the recorded flow rate indicates a zero value for about one second following crossfeed termination. From visual observation of the experiment the booster engine flow rate did not stop during testing. This indicates that the flow meter measurements are questionable during the rapid pressure transient at crossfeed termination and that the model flow rate predictions are reasonable.

Based on these results and the results of the entire test matrix ${ }^{2}$, it was shown that passive crossfeed is a viable concept to use with an RLV system. The presence of dissolved gas in the system caused frequency shifts in the upstream and downstream pressure signatures but the simulation of the crossfeed check valve closure was well characterized, sufficient for prediction of a TSTO vehicle concept. The predictions were developed of the full scale TSTO crossfeed system. The results indicated that the pressure transients in the full scale system were well within the engine run box requirement for an SSME type engine $e^{2,3}$.

\section{Conclusion}

Both the crossfeed test program and the newly developed models demonstrated that propellant crossfeed using passive termination with a check valve is feasible for a two-stage RLV architecture. The parallel modeling effort during the test program has shown reasonably good accuracy for transient simulation of a complex flow network. Accordingly, for complex flow devices such as the crossfeed check valve, the coupled EASY5-FLOW-3D approach performs better than using only EASY5 standard libraries. The developed methods can, therefore, be used with confidence for the design of complex space propulsion systems. When considering the rapid design iterations and mission simulations possible for new space systems and the large costs of testing in actual scale with real propellants, development and test costs for new propulsion systems can be minimized by demonstrating vehicle performance over a broad operating range with accurate detailed CFD simulations and validated transient computer models.

\section{Acknowledgments}

This paper is based on the work performed for National Aeronautics and Space Administration (NASA) Marshall Space Flight Center (MSFC) under NASA Contract No. NAS8-01099 of TA-8 Crossfeed Demonstration, under the technical leadership of Mr. Shayne Swint, Contracting Officer Technical Representative Designee; Dr. Tom Brown, Lead System Engineer; Mr. Pete Mazurkivich, Lead Subsystem Manager; and Mr. Chris Popp, Engineering Lead.

The Boeing TA-8 technical core team under leadership of Dr. Frank Chandler, Principal Investigator includes: Mr. Mike Scheiern, Deputy Principle Investigator; Mr. Alex Yi, Systems Engineer; Mr. Martin Lozano, Lead Test Article Engineer; Dr. Han Nguyen, Lead Pressurization Analyst; Mr. Gary Grayson, Lead CFD Analyst; Mr. Andy Messina, Test Engineer; Mr. Paul Labelle, Designer; Mr. Richard Nowels, Designer; Mr. Pat Rogers, Lead Lab \& Test; and Mr. Robert Van Vooren, Lab \& Test. The authors wish to thank Mr. Mike Stoia for his contribution to the development of several FLOW-3D CFD graphics. 
The Importance of Detailed Component Simulations in the Feedsystem Development for a Two-Stage-to-Orbit Reusable Launch Vehicle Figures 1-19

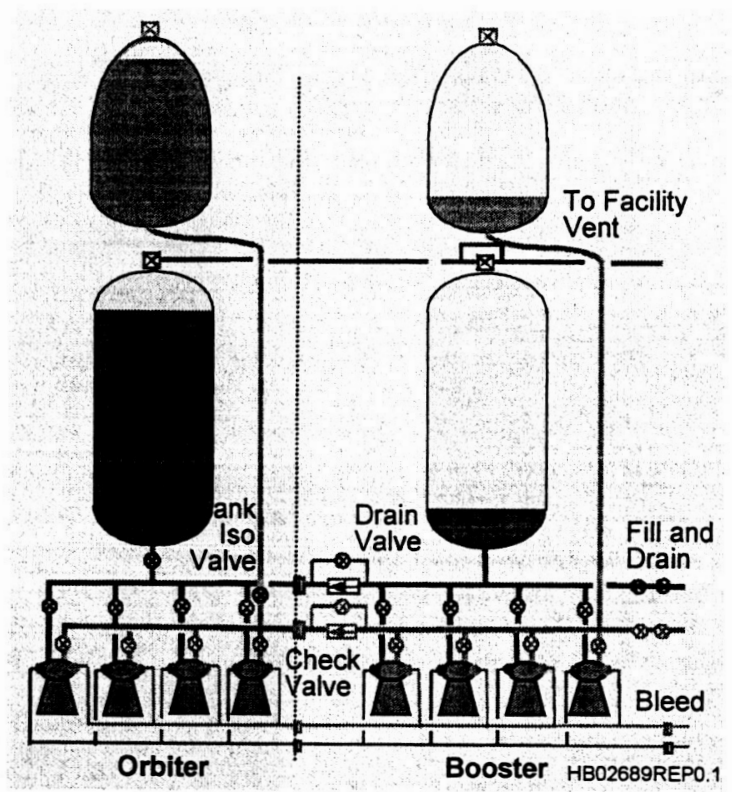

Figure 1. Hardware commonality reduces the number of new components, thereby decreasing costs and increasing reliability and safety.
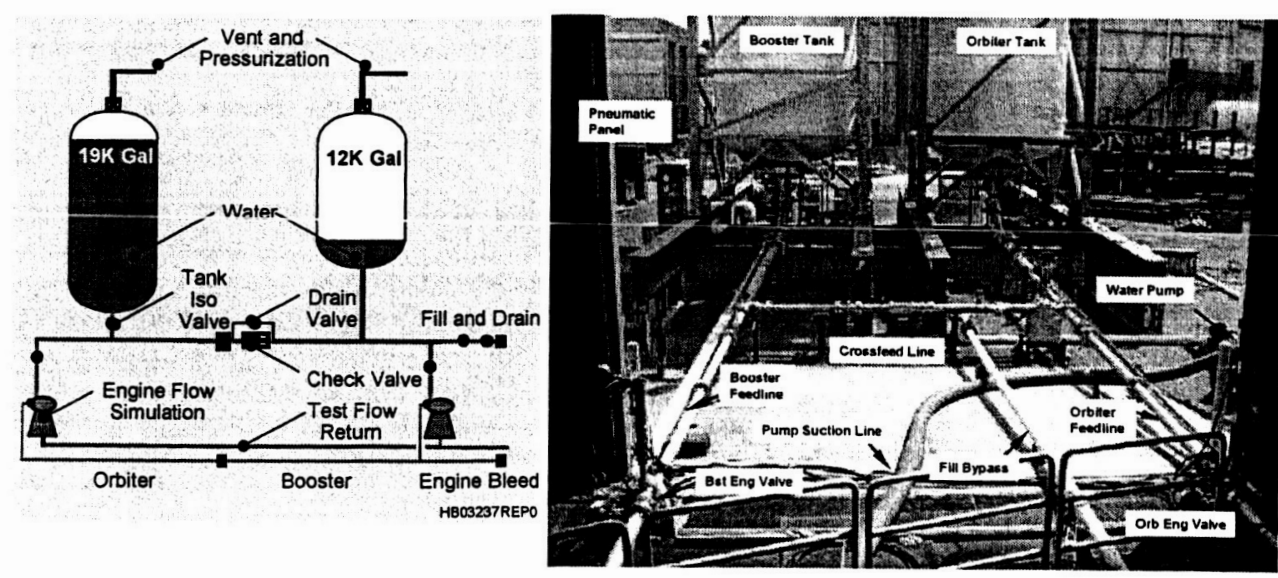

Figure 2. The crossfeed test article uses propellant qualified tanks to simulate the orbiter and booster tanks. 


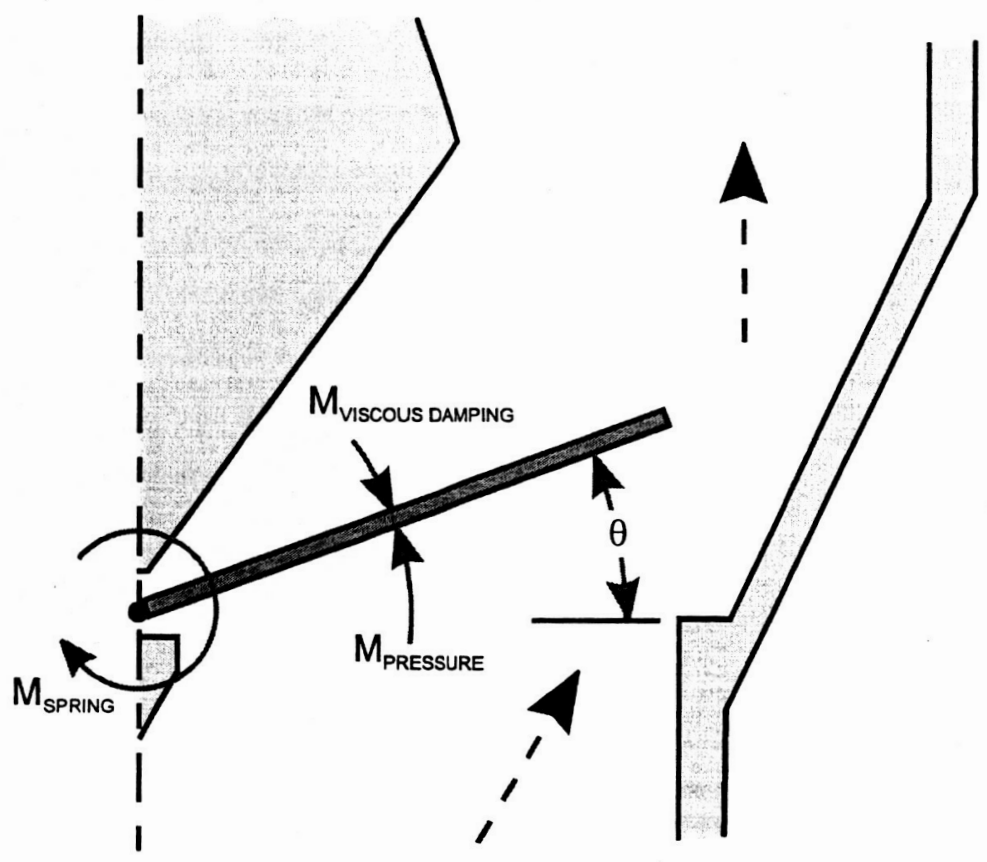

Fig. 3 Crossfeed Check Valve Free Body Diagram

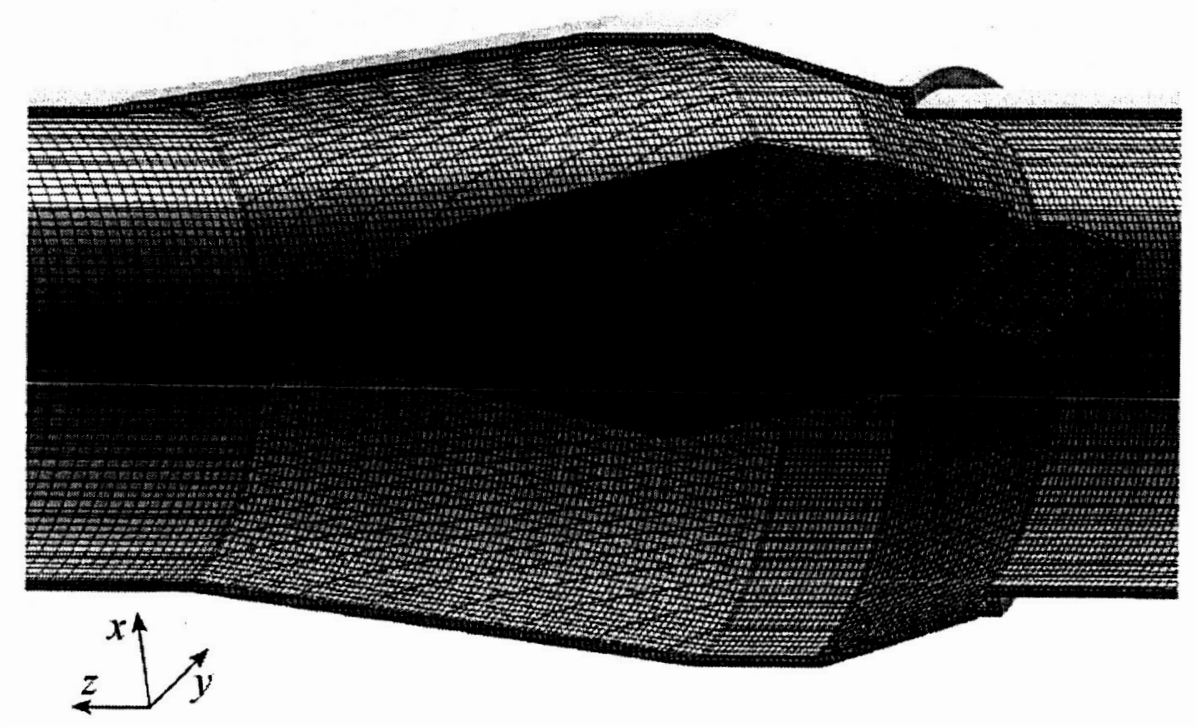

Fig. 4 Crossfeed Check Valve CFD Model 


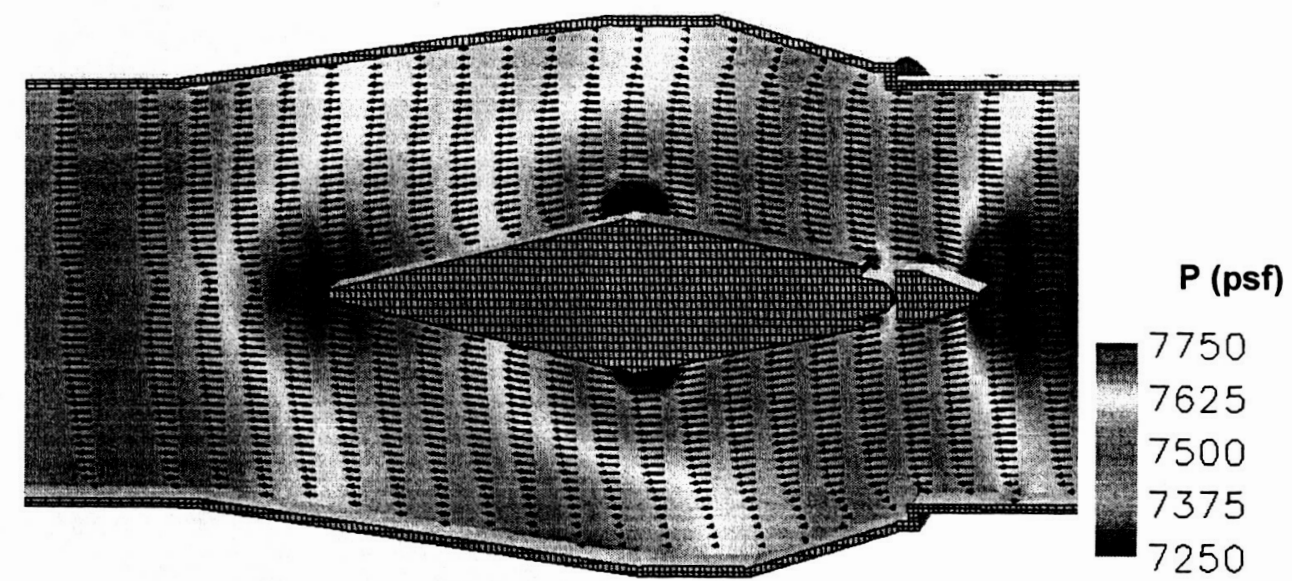

Fig. 5 Predicted Flow Field in Fully-Open Crossfeed Check Valve $(\theta=79 \mathrm{deg}$, flow rate $=135 \mathrm{lbm} / \mathrm{s})$

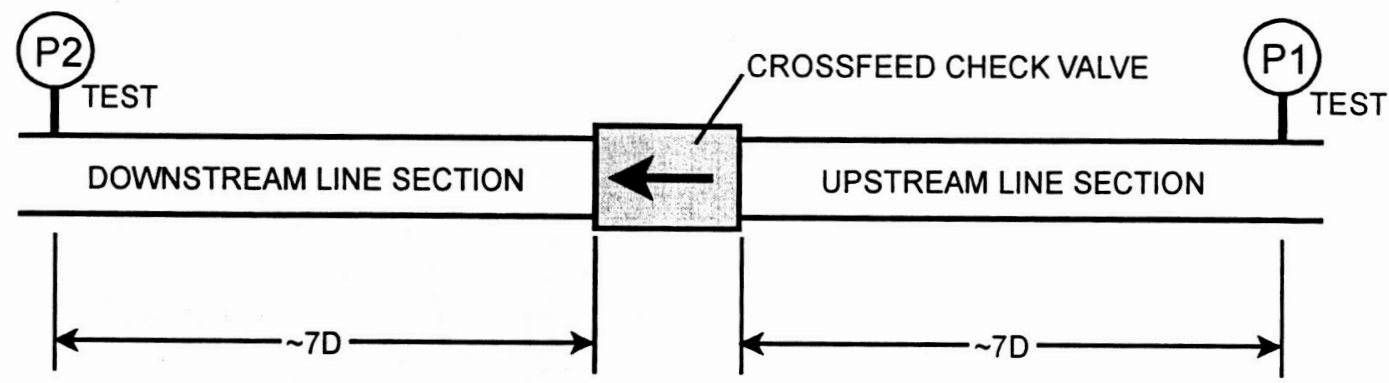

Fig. 6 Crossfeed Check Valve Pressure Drop Test Apparatus Schematic

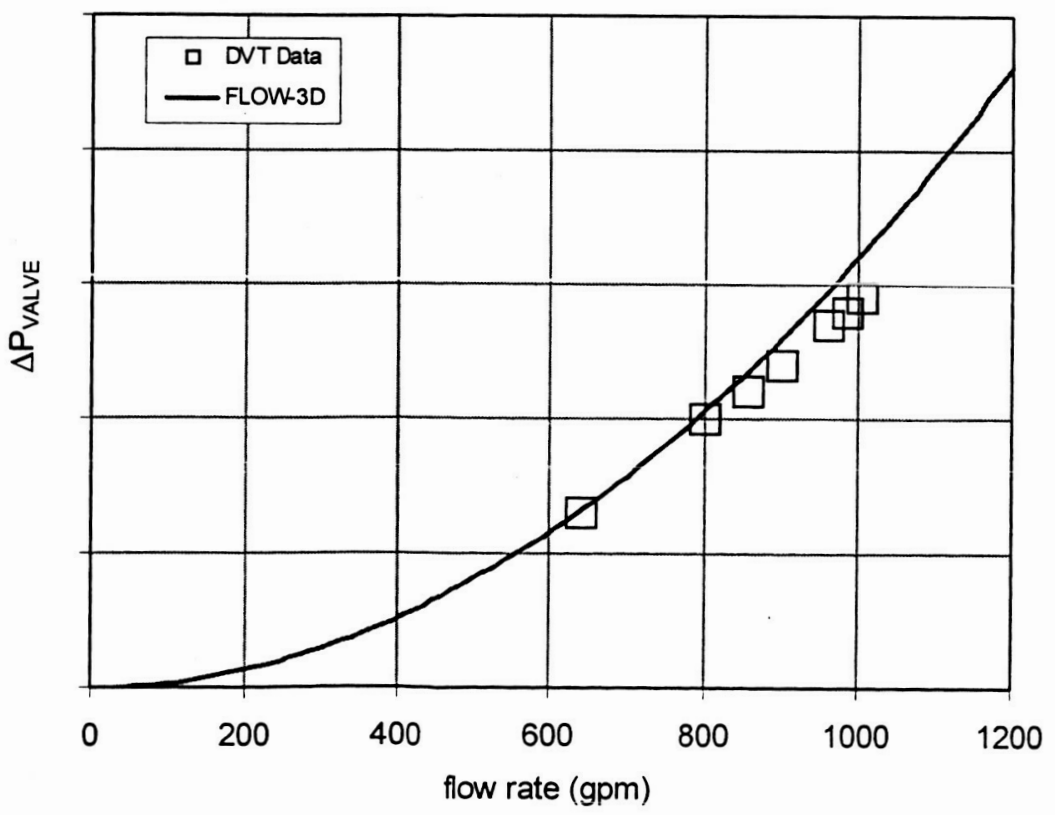

Fig. 7 CFD Model and Test Data Comparison 


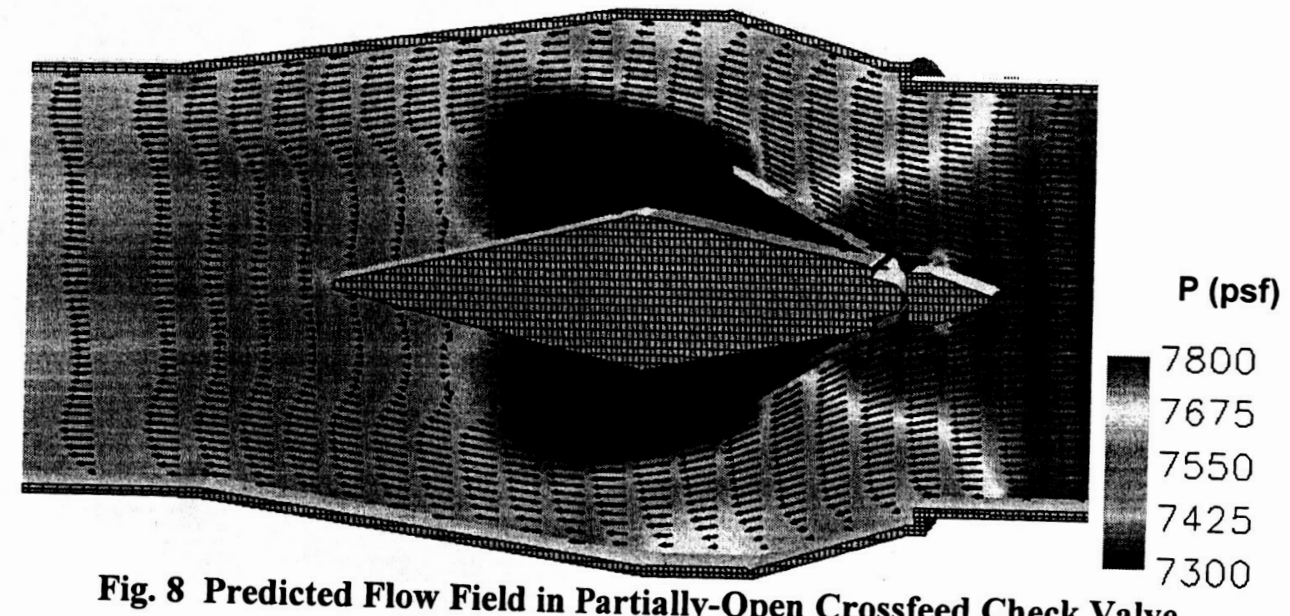

Fig. 8 Predicted Flow Field in Partially-Open Crossfeed Check Valve $(\theta=60 \mathrm{deg}$, flow rate $=128 \mathrm{lbm} / \mathrm{s})$

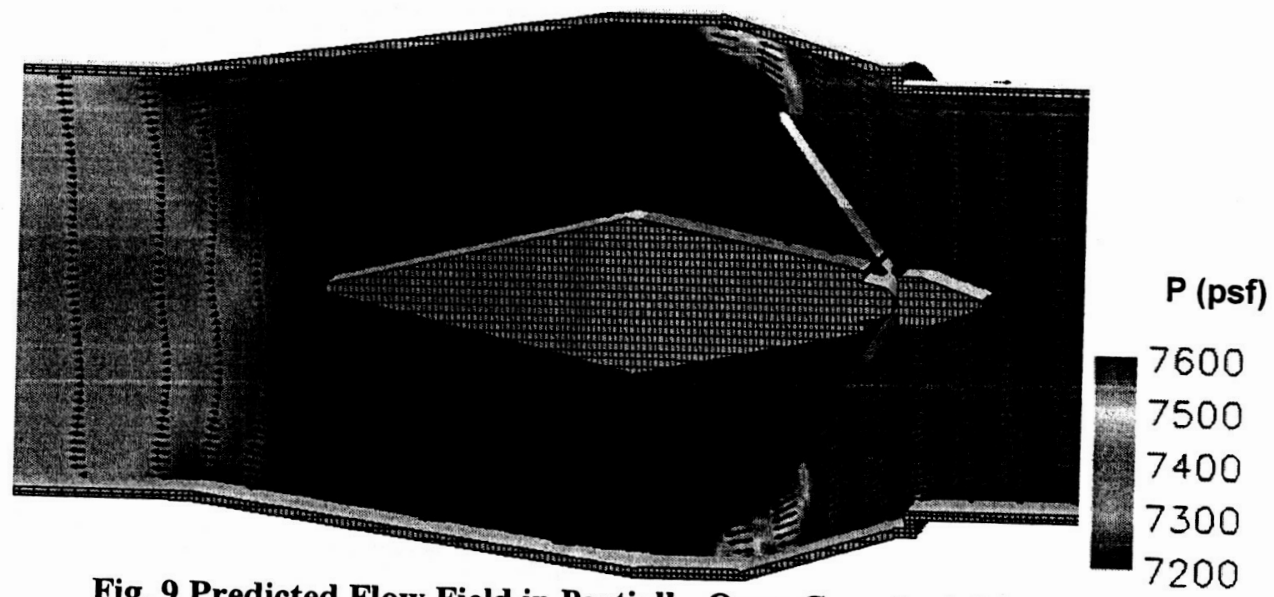

Fig. 9 Predicted Flow Field in Partially-Open Crossfeed Check Valve $(\theta=35 \mathrm{deg}$, flow rate $=90 \mathrm{lbm} / \mathrm{s})$

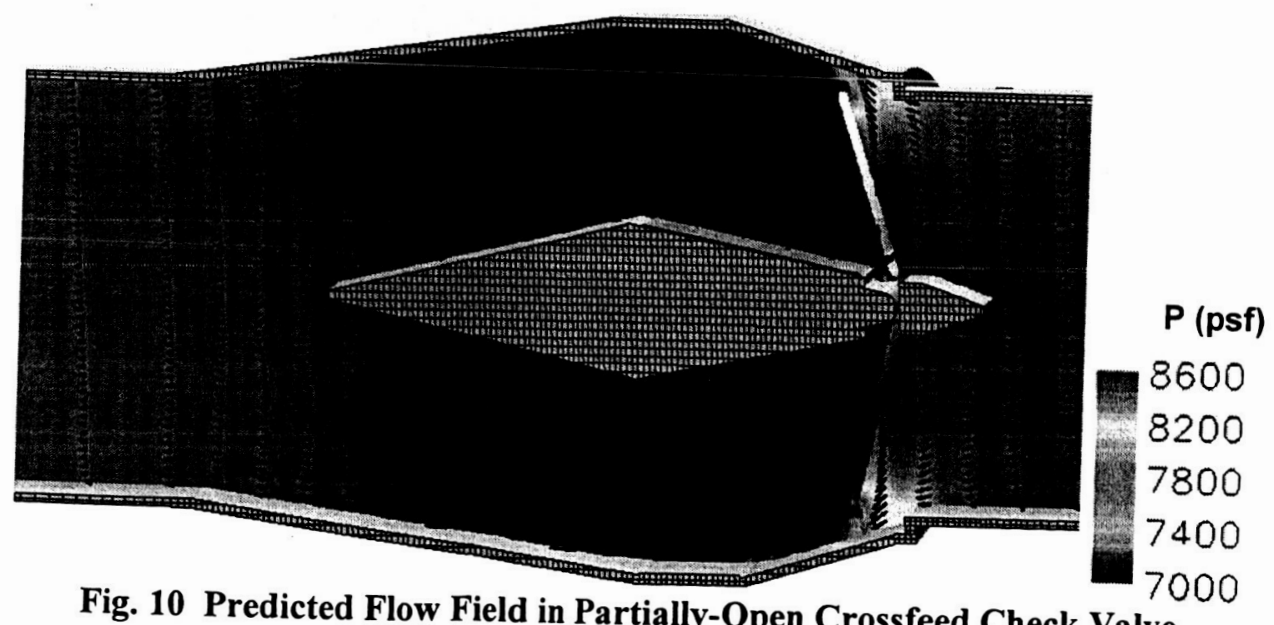
$(\theta=15 \mathrm{deg}$, flow rate $=46 \mathrm{lbm} / \mathrm{s})$ 


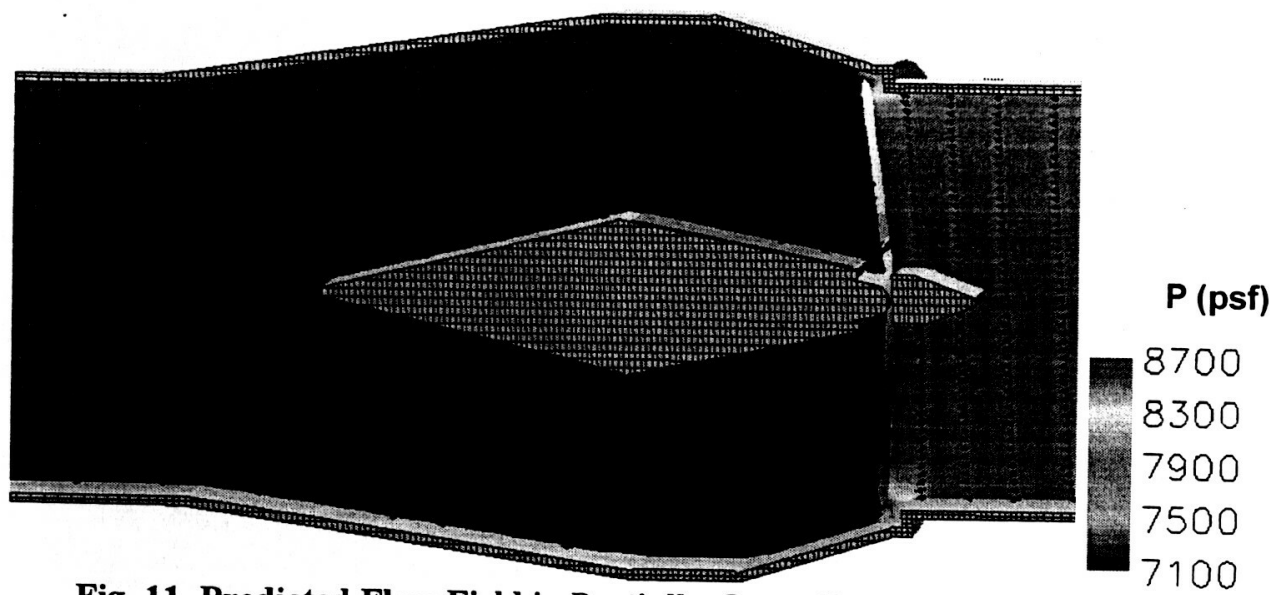

Fig. 11 Predicted Flow Field in Partially-Open Crossfeed Check Valve $(\theta=5 \mathrm{deg}$, flow rate $=29 \mathrm{lbm} / \mathrm{s})$ 


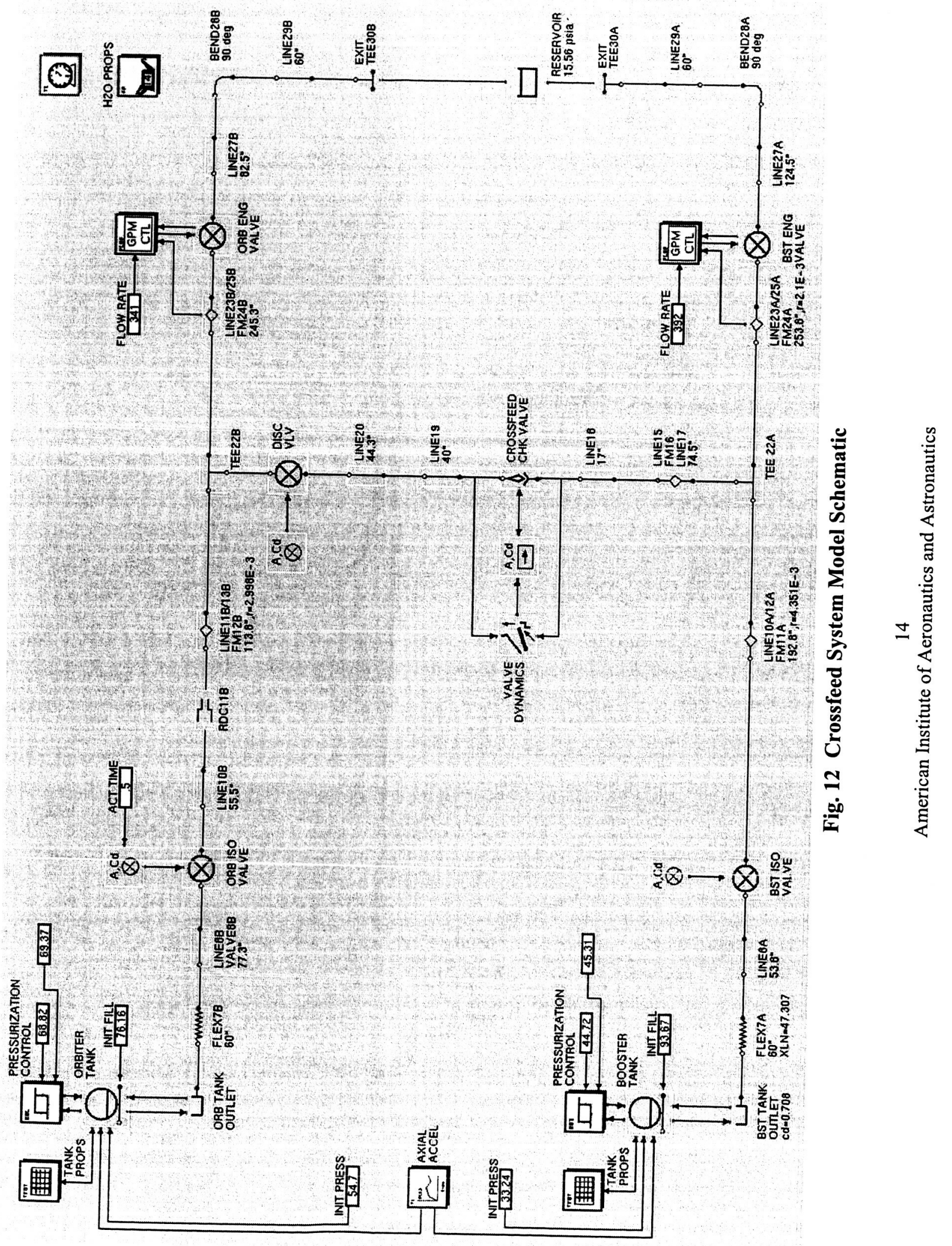



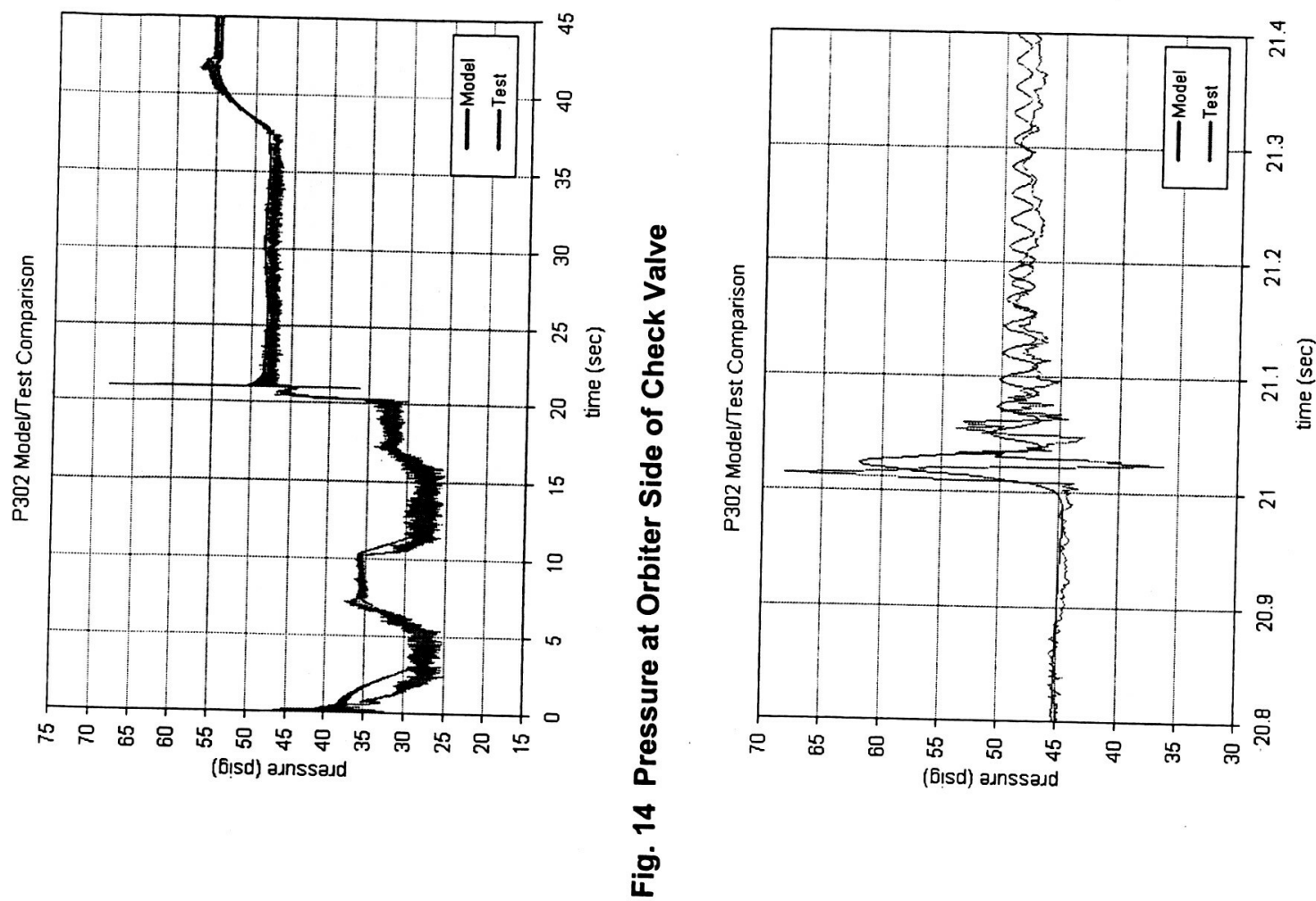

o
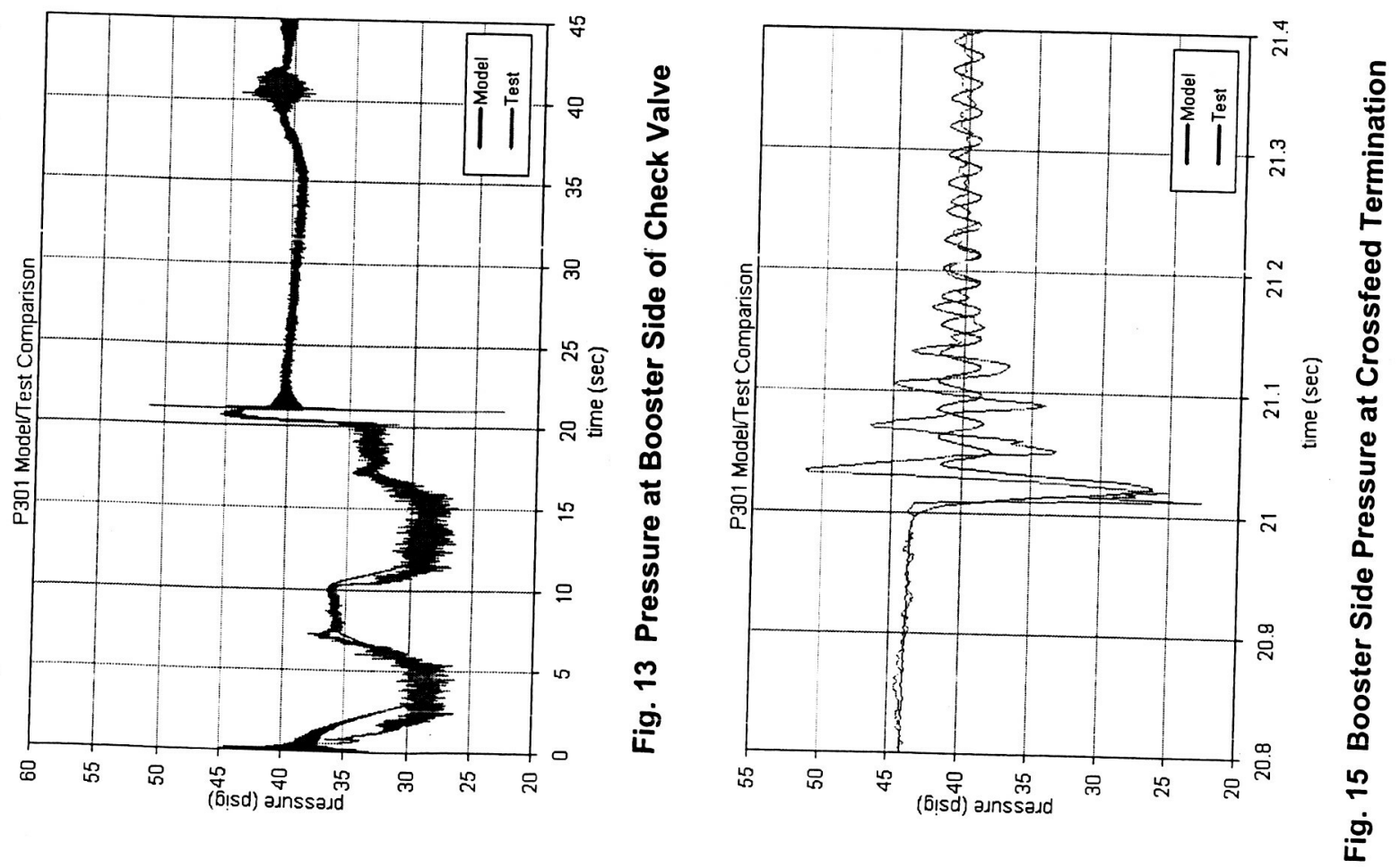

泀 

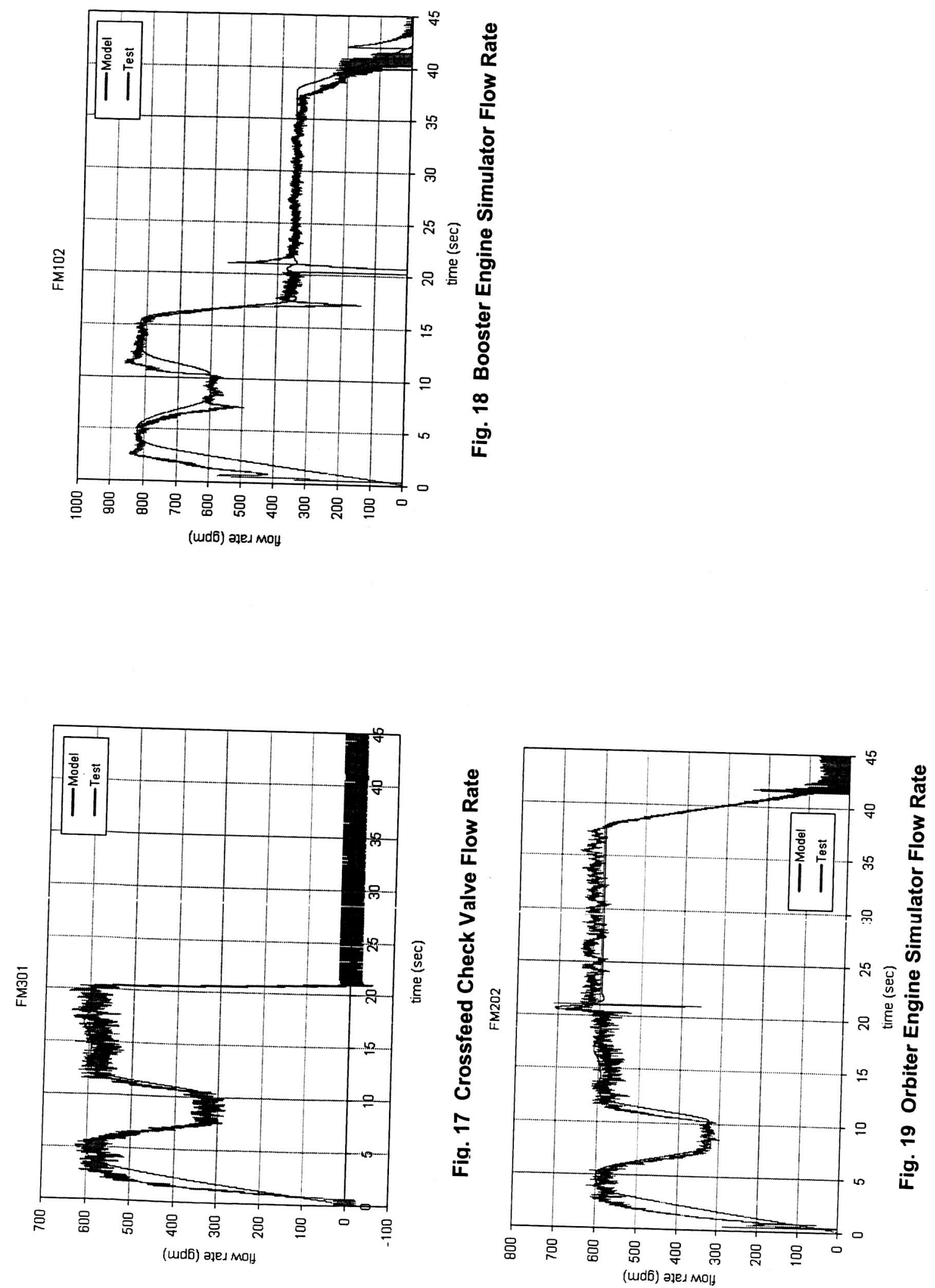


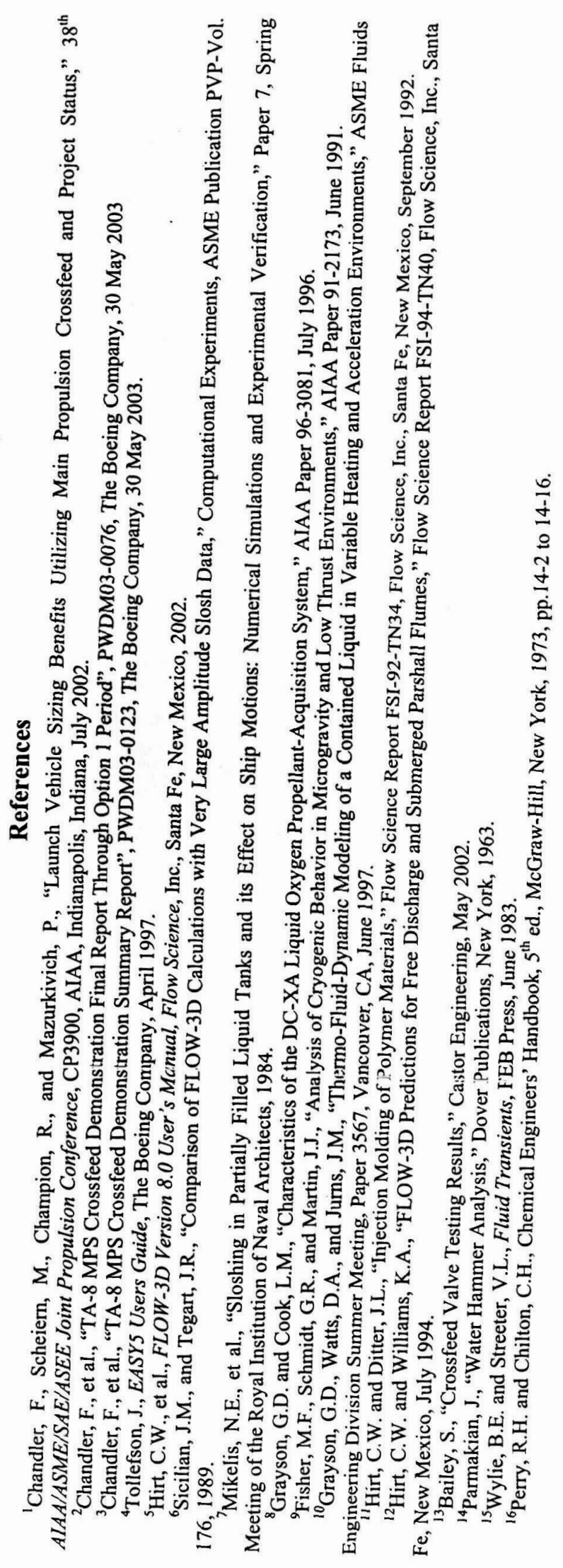

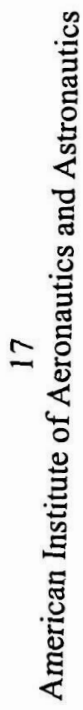

